\title{
Amok syndrome in a quadruple crime, acting out and pathological drive.
}

DOI: $10.46932 / \mathrm{sfjdv2n2-189}$

Received in: March 1st, 2021

Accepted in: May 30th, 2021

\author{
Dr. Bernat-Noël Tiffon Nonis \\ Universitat Abad Oliba -CEU. Calle de Bellesguard, no30. 08022 Barcelona (Spain). \\ E-mail: btiffonn@uao.es
}

\section{RESUME}

The concept of Amok Syndrome is described and reviewed and a case of murder of 4 victims perpetrated by a subject who, allowing himself to be seized by his outburst and anger, commits the criminalcriminological acts is described.

Keywords: Amok Syndrome, Pathological Impulsivity, Murders, Acting Out, Intermittent Explosive Disorder, Quadruple Murder

\section{INTRODUCTION:}

According to DSM-IV (1995), Amok is characterized by an acute episode of violent and uncontrolled behavior that the person does not later remember. Unlike Intermittent Explosive Disorder, Amok presents as a single episode rather than a pattern of aggressive behavior and is often associated with prominent dissociative traits. Violent behavior episodes are more frequent in males than in females.

Likewise, and although it is traditionally observed in Southeast Asian countries, cases of Amok have also been reported in Canada and the United States.

The DSM-IV Manual (1995) itself considers Amok as an Intermittent Explosive Disorder, but of rare prevalence, defining it as a dissociative episode characterized by a period of depression followed by a manifestation of violent, aggressive or homicidal behavior, directed at people and objects. The episode is triggered by the perception of disrespect or an insult and appears to be prevalent among men. The episode is frequently accompanied by paranoid ideas, automatism, amnesia, exhaustion, and a return to the premorbid state after the episode. On some occasions, Amok can appear during the presentation of a brief psychotic episode or constitute the beginning or an exacerbation of a chronic psychotic process. The original reports using this term were from Malaysia. For Esteban (2010), its origin is so old that it was already cited in a book by Portuguese Duarte Barbosa written in the 16th century, where this merchant who traveled with the Magellan expedition related the behavior of some inhabitants of the Indonesian island of Java: "The subject went out into the streets and killed as many people as he found." According to specialists, "the individual who suffers from it after suffering a strong social shame; begins to run incessantly destroying everything he finds in his path, even killing animals and people who bump into his 
way. Normally, the rest of the population ends up killing him for being a dangerous being, but those who survive, show total amnesia about what happened. It could be suggested that it is a panic attack, schizophrenia, or a transitory paranoia, but the truth is that Western specialists do not agree on the exact nature of amok".

A similar pattern of behavior is found in Laos, the Philippines, Polynesia (cafard or cathard), Papua New Guinea and Puerto Rico(fighting sickness), and among the Navajo population (iich'aa).

Regarding the course of this dysfunction, there are little data on the age of onset of an intermittent explosive disorder, but it can appear from late adolescence to the third decade of life. And the form of presentation is abrupt and without a prodromal period.

In order to diagnose such dysfunction, the diagnosis of Intermittent Explosive Disorder should only be considered after all disorders associated with impulsive or aggressive behaviors have been ruled out.

It should be noted, as the DSM-IV Manual itself (1995) says, the practice of a detailed clinical history and a complete neurological examination is useful to establish the prognosis. Nonspecific abnormalities on neurologic examination and nonspecific EEG changes are consistent with the diagnosis of an intermittent explosive disorder, provided that they are not the result of a diagnosable medical condition. Intermittent Explosive Disorder must be distinguished from aggressive or erratic behavior that may be manifested by individuals with Oppositional Defiant Disorder, Conduct Disorder, Antisocial Personality Disorder, Borderline Personality Disorder, a Manic Episode, and Schizophrenia. For this reason, if aggressive behavior is better explained by the presence of another mental disorder, the diagnosis of intermittent explosive disorder should not be made.

In this sense, in Amok Syndrome an aggressive behavior can appear in the absence of a mental disorder. Finalist behavior is distinguished from intermittent explosive disorder by the existence of incentives and gains from the aggressive act. In the forensic context, people can simulate an intermittent explosive disorder to avoid responsibility derived from their behavior (DSM-IV, 1995). For DSM-IV (1995) the criteria for the diagnosis of F63.8 Intermittent Explosive Disorder [312.34] are as follows:

1. Several isolated episodes of difficulty controlling aggressive impulses, leading to violence or property destruction.

2. The degree of aggressiveness during the episodes is disproportionate to the intensity of any precipitating psychosocial stressor 
3. Aggressive episodes are not better explained by the presence of another mental disorder (eg, antisocial personality disorder, borderline personality disorder, psychotic disorder, manic episode, conduct disorder, or attention deficit hyperactivity disorder) and they are not due to the direct physiological effects of a substance (eg, drugs, medications) or a general medical condition (eg, head injury, Alzheimer's disease).

In the present case, it is a 58-year-old male, native of a municipality in the province of Girona and with a single marital status. He ranks 1st. position of a 3 brothers' fratria. Its academic level is basic, reaching the Certificate of Primary Studies. His professional career has been practiced for 28-30 years as a bricklayer. As a clinical psychopathological history, the informed reported that when he was 8-9 years old, he suffered head trauma due to a bicycle accident (he adds that he was operated on, but that he does not have clinical documentation that collects such health professional action given the time elapsed).

The informed person was visited as a preventive inmate in a nearby penitentiary in the aforementioned province, waiting to be tried for a crime of 4 murders (quadruple crime). The Iter Criminis of the reported was as follows:

- 2 murders in a bar in a municipality in the province of Girona. The victims were father and son and were shot to death.

- 2 murders were perpetrated after about 15 minutes (approximately) in a savings bank in a municipality close to the previous one in the same province and whose distance between one and the other was about $11 \mathrm{~km}$ (approximately). The victims were workers at the bank branch. 
Figures 1 and 2: Reconstruction of the facts.
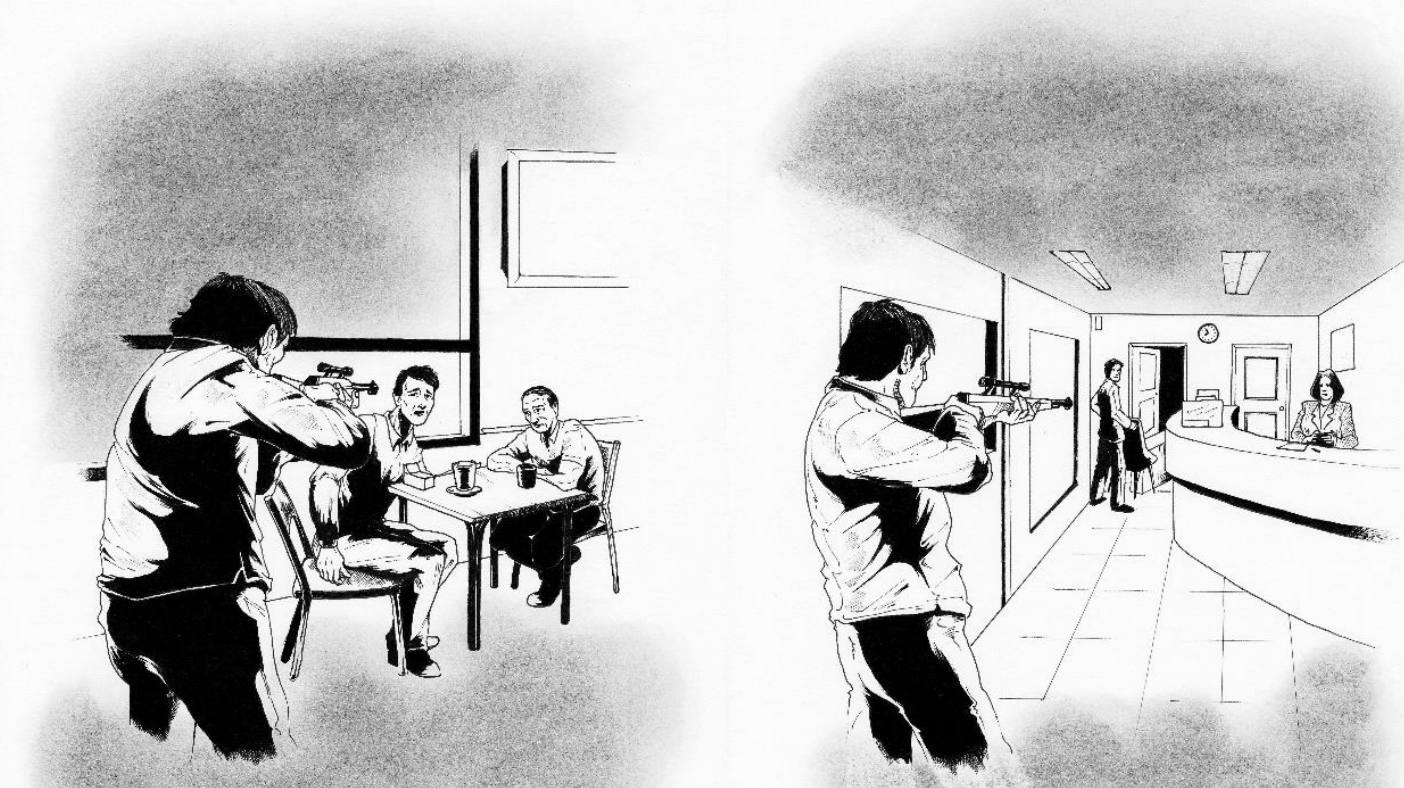

Illustrations by Juan Antonio Valverde. In Tiffon, N.-N. (2015). “Los Crímenes de Perejil”. Bosch Editor. Barcelona.

\section{RESULTS:}

For the development of the study of the personality of the informed person, the following methodology was followed:

1. Conducted clinical-expert interview (anamnesis) with the informed person with a total investment of approximately 4 hours. in a Penitentiary Center in the province of Barcelona.

2. Interview with the sister of the informed.

3. Updated administration of psychometric tests to evaluate his mental and psychopathological state (MMPI-2; MCMI-3, 16PF, TCI-R, Salamanca Questionnaire, STAI, BISS-11 pathological impulsivity, EMCA, Folstein MEC, and Pfeiffer Questionnaire).

4. Analysis of the clinical and legal documentation provided.

As a result of the administration of the psychopathological questionnaires and the different conducted clinical interviews held, the results obtained suggest that the reported person (perpetrator of the aggressions) presented compatibility with an Intermittent Explosive Disorder with a subclinical modality of pathological impulsivity of Amok's Syndrome in the precise moments and instants of the perpetration of the events that occurred and that were the subject of juridical-legal debate (both in the bar and in the savings bank). 


\section{DISCUSSION/CONCLUSIONS:}

In the context of psychopathological and criminological exploration and analysis of the Iter Criminis perpetrated by the aggressor and whose result of death was 4 adult victims ( 3 men and one woman), the informed person presented compatibility of psychic dysfunction of pathological impulsivity originally badly channeled by the rage and anger that he presented when he did not tolerate the frustration of not being properly paid professionally (Tiffon, 2015). Likewise, and after about 15 minutes of perpetrating the first criminally impulsive act in acting out, the perpetrator did not tolerate his frustration when claiming an amount indebted by the savings bank and perpetrated his second criminal act, killing 2 more people in the act with a firearm (shotgun).

Criminal-criminological behavior was the product of a set of basic psychopathological factors that acted as preconditions in the previously described behavioral materialization:

- Pathological impulsivity (understood as Impulsive Control Disorder, submodality of Intermittent Explosive Disorder).

- $\quad$ Mixed Personality Disorder.

- Neurocognitive impairment due to age factor and low academic-training level. 


\section{REFERENCES}

American Psychiatric Association (1995). "Diagnostic and Statistical Manual of Mental Disorders: DSMIV. Washington. Versión española de la cuarta edición de la obra original en lengua inglesa. 1995. MASSON, S.A. Barcelona (España).

Esteban, M. (2010). “Geografía del desarrollo humano”. Editorial Aresta. Barcelona.

Tiffon, B.-N. (2015). “Los Crímenes de Perejil”. Bosch Editor. Barcelona.

Tiffon, B.-N. y cols. (2017). “Atlas de Psicología Forense (Penal)”. J.M. Bosch Editor. Barcelona.

Tiffon, B.-N. y cols. (2019). “Atlas Práctico-Criminológico de Psicometría Forense (Volumen I): Asesinatos". J.M. Bosch Editor. Barcelona.

Tiffon, B.-N. y cols. (2019). “Atlas Práctico-Criminológico de Psicometría Forense (Volumen II): Tentativas de Asesinatos". J.M. Bosch Editor. Barcelona.

Tiffon, B.-N. y González-Fernández, J. (2021). “Amok Syndrome. Qualified perspectives on an agressive reaction of pathological impulsiveness in the perpetration of a double crime with a firearm". Asean Journal of Psychiatry. Vol. 22(S2), June 2021: 1-5.

Tiffon BN. "Atlas of Forensic Criminal Psychology". Taylor \& Francis Group-CRC Press. USA. In press. 2021. 